be returning to this country for leave, and for a period of work on her report, before returning to the field for her second tour in January next.

\title{
The Nederland Afrika Instituut
}

INTERNATIONAL problems have always ranked high among the subjects studied at Dutch Universities, and although Holland has no administrative interest in Africa, a knowledge of African problems is considered to be of value for the solution of future problems in Indonesia. The Nederland Afrika Instituut was founded in 1945 at Rotterdam by the Chamber of Commerce in co-operation with the School of Economics. The Institute is to be organized in two sections, that at Rotterdam being mainly concerned with economic and commercial information, while scientific research in ethnology, sociology, and colonial administration will be developed at Leiden, in co-operation with the University. A comprehensive library is being built up, and a periodical publication, containing factual information, mainly of a commercial nature, is issued. Dr. Idenburg, Secretary of the Institute at Leiden, and Dr. Kraemer, who is a member of the Council, called at the London office of the International African Institute during their visit to England, discussed their plans, and expressed their cordial desire for co-operation with this Institute.

\section{Two New Journals}

'Frve centuries ago our first Portuguese navigators landed, with eyes full open to all the novelty that the Dark Continent had to reveal; it is time that the country should have a more exact and conscious knowledge of its oldest colonial possession: time that the Portuguese should make a new discovery of Portuguese Guinea!' So writes Senhor Marcello Caetano, Minister of the Colonies, in his introduction to the first number of the Boletim cultural da Guine Portuguesa, which, with its wide programme, promises to fill a big gap in our knowledge. It opens most appropriately with a long article on the discovery of Guinea following Nuno Tristao's voyage in I446. One section of the Bulletin is to be devoted to ethnography.

The other new journal is Fort Hare Papers, edited by professors of the South African Native College and printed by the Lovedale press. No. 2 is fully occupied by a notable article by that promising Bantu scholar G. L. Letele on "The Noun Class-prefix in the Sotho Group of Bantu languages '. Those of our readers who know any of these languages will find here many new suggestions. It is a curious feature of classification that when a Jew is thought of merely as a Jew he is designated le-Juta, but a Jew referred to in the Bible is mo-Juta, that is to say, he is promoted to Class I. The analysis of nouns assigned to Class 7 (SE-) is particularly interesting; they are chiefly the names of persons and things with outstanding qualities, normal or abnormal-of spirits, as creatures abnormal in appearance and nature, sedimo, ' ghost', setho, ' ghost '; of sub-normal creatures, selehe, ' useless person', and so on. This section of his paper raises many questions and repays careful study. No. I contains two other articles by Africans : Professor Z. K. Matthews writes 'A Short History of the Tshidi Barolong' and Mr. G. I. M. Mzamane on the use of certain plants by Bantuspeaking peoples. Professor A. J. D. Meiring, honorary Curator of the F. S. Malan Museum, deals with engravings on Masarwa egg-shells. He thinks it probable that the apparent relationship between the Capsian and 'Bushman' cultures is due to parallel evolution. We hope that Principal Kerr is too pessimistic in saying ' it will not be possible to supply material for issue at regular intervals . 